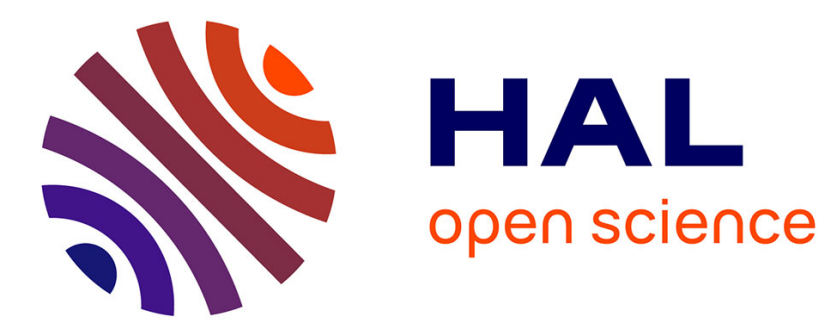

\title{
Organization of diglycolamides on resorcinarene cavitand and its effect on the selective extraction and separation of HREEs
}

\author{
M. Wehbie, Guilhem Arrachart, C. Arrambide Cruz, I. Karame, L. Ghannam, \\ S Pellet-Rostaing
}

\section{To cite this version:}

M. Wehbie, Guilhem Arrachart, C. Arrambide Cruz, I. Karame, L. Ghannam, et al.. Organization of diglycolamides on resorcinarene cavitand and its effect on the selective extraction and separation of HREEs. Separation and Purification Technology, 2017, 187, pp.311-318. 10.1016/j.seppur.2017.06.062 . hal-02062518

\section{HAL Id: hal-02062518 \\ https://hal.science/hal-02062518}

Submitted on 26 Oct 2021

HAL is a multi-disciplinary open access archive for the deposit and dissemination of scientific research documents, whether they are published or not. The documents may come from teaching and research institutions in France or abroad, or from public or private research centers.
L'archive ouverte pluridisciplinaire HAL, est destinée au dépôt et à la diffusion de documents scientifiques de niveau recherche, publiés ou non, émanant des établissements d'enseignement et de recherche français ou étrangers, des laboratoires publics ou privés. 


\title{
Organization of diglycolamides on resorcinarene cavitand and its effect on the selective extraction and separation of HREEs
}

\author{
M. Wehbie, ${ }^{a, b}$ G. Arrachart, ${ }^{* a}$ C. Arrambide, I. Karaméb, L. Ghannam, ${ }^{b}$ and S. Pellet-Rostaing ${ }^{* a}$ \\ aICSM, CEA, CNRS, Univ. Montpellier, ENSCM, 30207 Bagnols-sur-Cèze Cedex, France. \\ bLaboratory of Organometallic Catalysis and Coordination Chemistry, Department of Chemistry, Lebanese University, \\ Faculty of Sciences I, Beirut, Lebanon \\ *Corresponding author. E-mail: guilhem.arrachart@cea.fr , stephane.pellet-rostaing@cea.fr
}

\begin{abstract}
Two calix(4)resorcinarene based cavitands, one that contains four triazole units, calix(4)resorcinarenetetra(hexyltriazole) CR4-Tz LI, and another that contains four triazole diglycolamide units, calix(4)resorcinarene tetra(didecyldiglycolamidetriazole) CR4-Tz-DDDGA LII, were synthesized and fully characterized by IR, NMR, and MS. The efficiency of the two cavitands were compared toward the extraction of 7 lanthanides (Ce(III), Nd(III), Sm(III), Gd(III), Dy(III), $\mathrm{Er}(\mathrm{III}), \mathrm{Yb}(\mathrm{III}))$ in chloroform from $5 \mathrm{M} \mathrm{HNO}_{3}$. The extraction study showed that $\mathrm{LI}$, which contains only the triazole units, is unable to extract any of the targeted metals. The effects of the organization and diluents on the distribution coefficients and the selectivity of LII were also studied toward the same lanthanide series at the same acidity. The obtained results showed that the cavitand is selective toward heavy lanthanides irrespective of the diluents. The extraction and stripping experiments of the $7 \mathrm{Ln}(\mathrm{III})$ and the separation of Nd and Dy from a Fe-B-Nd-Dy leaching solution were performed.
\end{abstract}

\section{Keywords}

DGA; Click chemistry; Resorcinarene; Selective ion separation; Lanthanides

\section{Introduction}

The world demand for rare earth elements (REEs) is progressively increasing due to their importance in high-technology industries. The REEs comprise a total of 17 elements in the periodic table, including the 15 lanthanides, as well as scandium and yttrium due to their similar properties. These elements can be extracted primarily from the bastnaesite and monazite ores [1]. Alternatively, they can be obtained from phosphogypsum [2] or by recycling the waste of electrical and electronic equipment's (WEEE) [3]. Over the past four decades, numerous innovations in the technological sectors have seen dramatic growth, causing an increase in the demand and the cost of REEs and consequently leading to a shortage in the supply lines [4]. Since the current mining will not be able to satisfy the increases in the REE demand, the development of economically exploitable rare earth deposits and of original resources and technologies to meet the future rare earth metal needs is encouraged [5]. Recycling of WEEE can reduce the stress and shortages resulting from the increasing demand for these highly important elements [6].

The REEs are separated into two categories, light rare earth elements (LREES), ranging from lanthanum (atomic number equal to 57) through gadolinium (atomic number equal to 64), and heavy rare earths elements (HREEs), ranging from terbium (atomic number equal to 65) through lutetium (atomic number equal to 71), as well as yttrium (atomic number equal to 39 ). Along the $4 \mathrm{f}$ block, as the atomic number increases, the number of electrons in the $4 \mathrm{f}$ shell increases; consequently, a stronger electrostatic attraction is generated between the $4 \mathrm{f}$ electrons and the nuclear charge, leading to the shrinkage in the ionic radii. This phenomenon is known as the "lanthanide contraction". Thus, the ionic radii of lanthanides decrease from 1.06 to $0.88 \AA$ from left to right across the lanthanides series [7]. Therefore, the HREEs with their larger nuclear charges and smaller ionic radii generate higher charge densities than the LREEs. Additionally, the regular decrease in atomic size of the REEs involves a gradual decrease in the basicity of the trivalent rare earth ions and therefore an increase in the stability of complexes along the lanthanide series.

The extremely slow decrease in basicity makes it very difficult to separate individual rare earths from a complex mixture of rare earths [8].

Based on Pearson's HSAB concept [9], HREEs are considered to be hard acids, and they are strongly bound by hard bases, such as oxygen donor atoms (e.g., malonamides and dyglycolamides) [10]. Diglycolamides (DGA) derivatives are the most promising extractants and are more efficient than malonamides because they form stable complexes with lanthanides and actinides by means of tridentade O-donating ligands [11]. The principal advantage of diamides over other phosphorous functions is their complete incineration and that the formed degradation products can be easily removed [12].

It is well-known that the organization of DGA sites on the preorganized macrocyclic platforms can have superior efficiency at lower concentration than TODGA [13]. Iqbal et al. [13a] Huang et al. [14] and Wu et al. [15] have organized DGA moieties on calixarene/pillararene platforms using nucleophilic substitution of the amino calixarene/pillararene with activated nitrophenol DGA systems and investigated the synthesized platforms toward An/Ln separation. In our previous work, we organized DGA systems on C-methylcalix(4)methyl-resorcinarene platform using amide coupling [16] or copper catalysed alkyl-azide cycloaddition [17], one of the most easiest, selective, reliable and quantitative reaction under mild conditions [18]. Resorcinarene has been chosen as the specific platform because of its conformational rigidity and its excellent preorganized platform for the coordination of host systems [19]. The extraction profile of calix(4)resorcinarene with triazole-DGA side arms 
CR4-Tz-DODGA showed higher efficiency at 5MHNO3 with high selectivity toward HREEs. In other words, the trend in extraction performance appears to be related to the charge density of the metal ion and to the rigidity of the cavitand.

To obtain the best insight into the performance of calix(4)resorcinarene with the triazole-DGA side arms, in the present work, we have synthesized two cavitands: the first has four triazole-DGA side arms (CR4-Tz-DDDGA), and the other has only four triazoles side arms (CR4-Tz) (Fig. 1). The cavitands' efficiency toward the extraction of seven lanthanides was studied in order to determine whether the triazole rings influence the extraction of lanthanides.

The influence of diluents on the extraction performance and selectivity of CR4-Tz-DDDGA was studied. In addition, the extraction and stripping of simulated solution of permanent magnets also have been successfully performed.

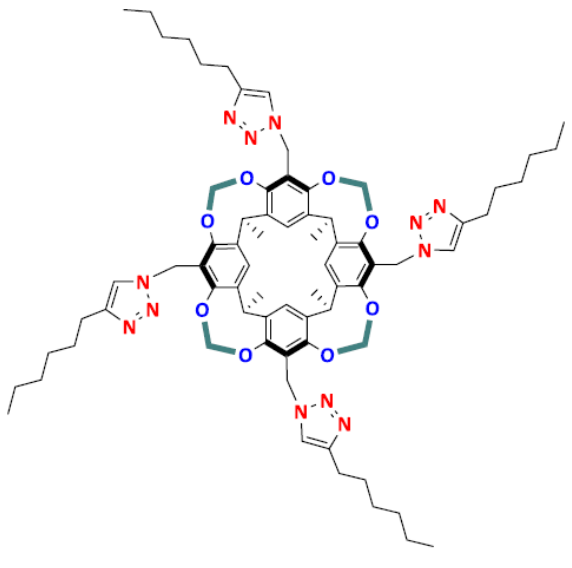

CR4-Tz $=\mathrm{LI}$

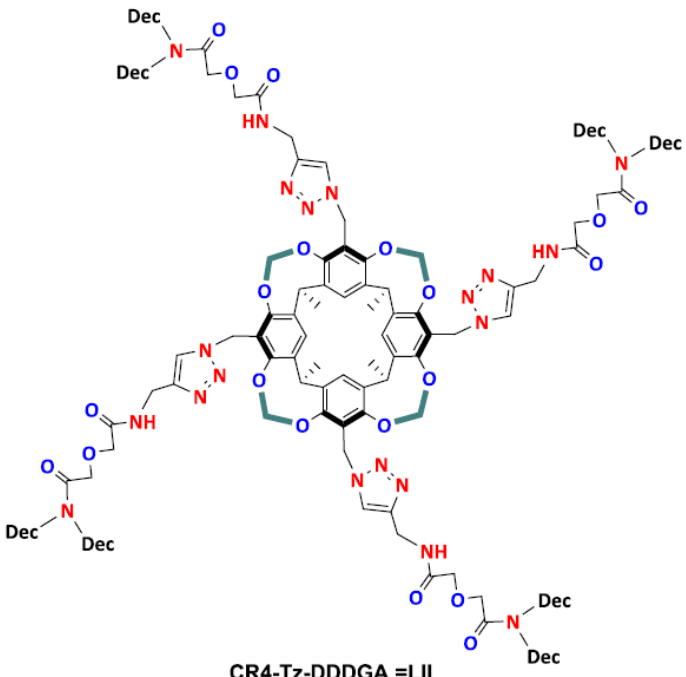

Fig. 1. Structures of CR4-Tz (LI), CR4-Tz-DDDGA (LII).

\section{Materials and methods}

\subsection{Chemicals and analysis}

Chemicals (analytically pure) were purchased from Sigma-Aldrich or Alfa Aesar and were used without further purification. Anhydrous solvents were purchased from Acros $\left(\right.$ AcroSeal $\left.^{\circledR}\right)$. Reactions were monitored by thin layer chromatography (Merck TLC Silica Gel 60 F254). NMR analyses were performed using a Bruker 400 ultrashield VS spectrometer. Displacements are reported in ppm using the solvent $\left(\mathrm{CDCl}_{3}: 7.26 \mathrm{ppm}\right.$ for ${ }^{1} \mathrm{H} ; 77.16 \mathrm{ppm}$ for $\left.{ }^{13} \mathrm{C}\right)$ as an internal reference.

Metal concentrations were measured by inductively coupled plasma/atomic emission spectroscopy (ICP/AES) using a SPECTRO ARCOS spectrometer. Fourier transform infrared (FTIR) measurements were performed using a Perkin Elmer Spectrum 100 instrument in the ATR (Attenuated Total Reflection) mode. The wavenumber measurement range was from 4000 to $400 \mathrm{~cm}^{-1}$ with the beam resolution of $4 \mathrm{~cm}^{-1}$. Background acquisition was performed prior to the measurements. ESIMS was performed on a Flexar SQ 300 MS instrument.

\subsection{Synthesis}

The general synthetic route for the calix(4)resorcinarene based cavitands is illustrated in Fig. 2.

\subsubsection{Synthesis of compound 1 (DDDGA)}

In this experiment, $1.76 \mathrm{~g}$ of diglycolic anhydride $(15.13 \mathrm{mmol})$ was dissolved in THF $(20 \mathrm{~mL})$, and $3 \mathrm{~g}$ of didecyl amine $(10.09$ $\mathrm{mmol}$ ) were added. The resulting solution was stirred for $24 \mathrm{~h}$ after which the solvent was evaporated, and the crude product was dissolved in $\mathrm{CH}_{2} \mathrm{Cl}_{2}(30 \mathrm{~mL})$ and washed three times with $\mathrm{H}_{2} \mathrm{O}(30 \mathrm{~mL})$. The organic phase was then dried over anhydrous $\mathrm{Na}_{2} \mathrm{SO}_{4}$, filtered and then the solvent was evaporated under reduced pressure to give $3.71 \mathrm{~g}$ of 1 as white product with an $89 \%$ yield.

${ }^{1} \mathrm{H} \mathrm{NMR}\left(400 \mathrm{MHz}, \mathrm{CDCl}_{3}\right) \delta[\mathrm{ppm}]: 0.89(\mathrm{~m}, 6 \mathrm{H}, \mathrm{CH} 2-\mathrm{CH} 3), 1.27$ (bs, 28H, -NCH2-CH2-(CH2)7-CH3), 1.56 (m, 4H, NH-CH2-CH2), $3.1(\mathrm{t}, 2 \mathrm{H}, \mathrm{J}=8.0 \mathrm{~Hz}, \mathrm{~N}-\mathrm{CH} 2), 3.36(\mathrm{t}, 2 \mathrm{H}, \mathrm{J}=8.0 \mathrm{~Hz}, \mathrm{~N}-\mathrm{CH} 2), 4.22(\mathrm{~s}, 2 \mathrm{H}, \mathrm{CO}-\mathrm{CH} 2-\mathrm{O})$, and 4.4 (s, 2H, O-CH2-CO).

${ }^{13} \mathrm{C} \mathrm{NMR}\left(100 \mathrm{MHz}, \mathrm{CDCl}_{3}\right) \delta[\mathrm{ppm}]: 14.1,22.6,22.7,26.8,26.9,27.4,28.6,29.24,29.29,29.31,29.4,29.5,31.8,31.9,46.9(\mathrm{~N}-$ $\mathrm{CH} 2), 71.2(\mathrm{CO}-\mathrm{CH} 2-\mathrm{O}), 73.0(\mathrm{O}-\mathrm{CH} 2-\mathrm{CO}), 170.6(\mathrm{C}=\mathrm{O})$, and $171.8(\mathrm{C}=\mathrm{O})$.

\subsubsection{Preparation of propargyl-DDDGA (2)}

For this experiment, $1.62 \mathrm{~g}$ of 2-(2-(didecylamino)-2-oxoethoxy) acetic acid $1[17,20],(4.54 \mathrm{mmol})$ and $0.675 \mathrm{~g}$ of hydroxyl benzotriazole $(4.99 \mathrm{mmol})$ were poured into $30 \mathrm{~mL}$ of chloroform in a round bottomed flask at $0^{\circ} \mathrm{C}$, then $1.03 \mathrm{~g}$ of dicyclohexylcarbodiimide DCC (4.99 $\mathrm{mmol})$ was added, and the obtained mixture was stirred for $30 \mathrm{~min}$ at room temperature. Next, $0.25 \mathrm{~g}$ of propargyl amine $(9.08 \mathrm{mmol})$ was added to the resulting suspension, and the obtained reaction mixture was stirred for two days. After filtration, the filtrate was washed with water $(2 \times 30 \mathrm{~mL}), 1 \mathrm{M} \mathrm{HCl}(2 \times 30 \mathrm{~mL})$ and then with a 
saturated solution of $\mathrm{NaCl}(2 \times 30 \mathrm{~mL})$. The organic collections were then dried over anhydrous $\mathrm{Na}_{2} \mathrm{SO}_{4}$ and then evaporated under vacuum to afford compound $\mathbf{2}$ as a brown dense oil with a $72 \%$ yield.

${ }^{1} \mathrm{H} \mathrm{NMR}\left(400 \mathrm{MHz}, \mathrm{CDCl}_{3}\right) \delta$ [ppm]: 0.90 (m, 6H, CH2-CH3), $1.29(\mathrm{~m}, 28 \mathrm{H},-\mathrm{NCH} 2-\mathrm{CH} 2-(\mathrm{CH} 2) 7-\mathrm{CH} 3), 1.55$ (m, 4H, NH-CH2-CH2), $2.21(\mathrm{t}, 1 \mathrm{H}, \mathrm{J}=2.4 \mathrm{~Hz}, \equiv \mathrm{CH}), 3.1(\mathrm{t}, 2 \mathrm{H}, 7.6 \mathrm{~Hz}, \mathrm{~N}-\mathrm{CH} 2), 3.33(\mathrm{t}, 2 \mathrm{H}, 7.6 \mathrm{~Hz}, \mathrm{~N}-\mathrm{CH} 2), 4.09$ (d, 2H, J = 2.8 Hz, NH-CH2), 4.1 (s, $2 \mathrm{H}$, CO-CH2-O), 4.25 (s, 2H, O-CH2-CO), $8.1(\mathrm{~s}, 1 \mathrm{H}, \mathrm{NH}-\mathrm{C}=\mathrm{O})$.

${ }^{13} \mathrm{C} \mathrm{NMR}\left(100 \mathrm{MHz}, \mathrm{CDCl}_{3}\right) \delta[\mathrm{ppm}]: 14.1,22.7,26.8,27.0,27.6,28.6(\mathrm{NH}-\mathrm{CH} 2-\mathrm{C} \equiv \mathrm{C}), 28.9,29.2,29.3,29.4,29.5,29.6,31.9$,

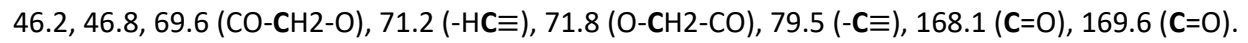

\subsubsection{Preparation of cavitand $\mathrm{LI}: \mathrm{CR} 4-\mathrm{TZ}$}

In this experiment, $0.11 \mathrm{~g}$ of octyne $(1 \mathrm{mmol}), 0.2 \mathrm{~g}$ of the azide $3(0.25 \mathrm{mmol}), 0.023 \mathrm{~g}$ of the catalyst [CuBr(PPh3)3] $(0.024$ $\mathrm{mmol}$ ), and $1 \mathrm{~mL}$ of dry trimethylamine were poured in $2 \mathrm{~mL}$ THF. The resulting solution was refluxed for $24 \mathrm{~h}$ at $80^{\circ} \mathrm{C}$. The reaction mixture was allowed to cool, and then the solvents were removed under vacuum. The crude product was dissolved in a mixture of pentane $/ \mathrm{CH}_{2} \mathrm{Cl}_{2} 5 \%$ and cooled down to precipitate out the catalyst that was filtered off and then the organic solvents were evaporated under reduced pressure to afford $\mathrm{LI}$ as a cream powder with $80 \%$ yield.

${ }^{1} \mathrm{H} \mathrm{NMR}\left(400 \mathrm{MHz}, \mathrm{CDCl}_{3}\right) \delta$ [ppm]: 0.89 (bs, 12H, CH2-CH3), 1.31 (bs, 24H, - CH2-(CH2)3-CH3), 1.64 (bs, 8H, Tz-CH2-CH2), 1.79 (bs, 12H, CH-CH3), 2.69 (bs, 8H, Tz-CH2), 4.34 (bs, $4 \mathrm{H}$, innerOCH2O), 5.01 (bs, $4 \mathrm{H}, \mathrm{CH}-\mathrm{CH} 3$ ), 5.25 (s, 8H, Ar-CH2-Tz), 5.84 (bs, $4 \mathrm{H}$, outer $\mathrm{OCH} 2 \mathrm{O}$ ), 7.36 (bs, $8 \mathrm{H}, \mathrm{ArH}$ and $\mathrm{TzCH}$ ).

${ }^{13} \mathrm{C} \mathrm{NMR}\left(100 \mathrm{MHz}, \mathrm{CDCl}_{3}\right) \delta$ [ppm]: 14.1, 16.2, 22.6, 25.7, 29.0, 29.4, 31.2 (Ar-CH-CH3), 31.6, 43.8 (Ar-CH2-Tz), 99.4 (O-CH2O), $120.7(\mathrm{TzCH}), 120.8(\mathrm{Ar}-\mathrm{CH}), 133.9,139.0,148.5(\mathrm{TzC}), 153.4$; ESI-MS (m/z): 1254[(M+H)+], 1276 [(M+Na) $\left.)^{+}\right]$; FT-IR (ATR crystal): $v\left(\mathrm{~cm}^{-1}\right) 1643(v \mathrm{C}=0)$.

\subsubsection{Preparation of cavitand LII: CR4-TZ-DDDGA}

For this step, $0.2 \mathrm{~g}$ of alkyne-DDDGA $2(0.512 \mathrm{mmol}), 0.104 \mathrm{~g}$ of the azide $3(0.128 \mathrm{mmol}), 0.005 \mathrm{~g}$ of the catalyst [CuBr$\left.\left(\mathrm{PPh}_{3}\right)_{3}\right]$ $(0.005 \mathrm{mmol})$, and $1 \mathrm{~mL}$ of dry trimethylamine were poured in $5 \mathrm{~mL}$ THF. The resulting solution was refluxed for $24 \mathrm{~h}$ at $80^{\circ} \mathrm{C}$. The reaction mixture was allowed to cool, and then the solvents were removed under vacuum. The crude product was dissolved in a mixture of pentane $/ \mathrm{CH}_{2} \mathrm{Cl}_{2} 5 \%$ and cooled down to precipitate out the catalyst that was filtered off; the organic solvents were then evaporated under reduced pressure to afford LII as a brown powder with $85 \%$ yield.

${ }^{1} \mathrm{H} \mathrm{NMR}\left(400 \mathrm{MHz}, \mathrm{CDCl}_{3}\right) \delta$ [ppm]: $0.88(\mathrm{~m}, 24 \mathrm{H}, \mathrm{CH} 2-\mathrm{CH} 3), 1.26(\mathrm{~m}, 112 \mathrm{H},-\mathrm{CH} 2-(\mathrm{CH} 2) 7-\mathrm{CH} 3), 1.5(\mathrm{~m}, 16 \mathrm{H}, \mathrm{NH}-\mathrm{CH} 2-\mathrm{CH} 2)$, $1.77(\mathrm{~d}, 12 \mathrm{H}, \mathrm{J}=6.8 \mathrm{~Hz}, \mathrm{CHCH} 3), 3.1(\mathrm{t}, 8 \mathrm{H}, 7.2 \mathrm{~Hz}, \mathrm{~N}-\mathrm{CH} 2), 3.3(\mathrm{t}, 8 \mathrm{H}, 7.2 \mathrm{~Hz}, \mathrm{~N}-\mathrm{CH} 2), 4.09$ (s, 8H, CO-CH2-O), 4.23 (s, $12 \mathrm{H}, \mathrm{O}-$ $\mathrm{CH2}-\mathrm{CO}$ and inner OCH2O(AB system)), 4.55 (s, 8H, Tz-CH2-NH), 4.98 (q, $4 \mathrm{H}, \mathrm{J}=6.8 \mathrm{~Hz}, \mathrm{CH}-\mathrm{CH} 3), 5.26$ (s, 8H, Ar-CH2-Tz), 5.82 $(\mathrm{m}, 4 \mathrm{H}, \mathrm{J}=6.8 \mathrm{~Hz}$, outer $\mathrm{OCH} 2 \mathrm{O}(\mathrm{AB}$ system)), $7.32(\mathrm{~s}, 4 \mathrm{H}, \mathrm{ArH}), 7.6(\mathrm{~s}, 4 \mathrm{H} \mathrm{TzCH}), 8.08(\mathrm{~m}, 4 \mathrm{H}, \mathrm{NH})$.

${ }^{13} \mathrm{C}$ NMR $\left(100 \mathrm{MHz}, \mathrm{CDCl}_{3}\right) \delta$ [ppm]: 14.1, 16.2, 22.6, 26.9, 27.1, 27.7, 28.9, 29.26, 29.29, 29.32, 29.41, 29.51, 29.55, 29.59, 31.2 (Ar-CH-CH3), 31.8, 31.9, 34.6, 44.0, 46.2, 46.8, 69.5, 71.5, 99.7 (O-CH2-O), 120.7 (Ar-CH), 122.8 (TzCH), 132.7, 138.9, $144.7(\mathrm{TzC}), 153.4,168.1(\mathrm{CO}-\mathrm{N}), 169.7(\mathrm{CO}-\mathrm{N}) ; \mathrm{ESI}-\mathrm{MS}(\mathrm{m} / \mathrm{z}): 2616\left[(\mathrm{M}+\mathrm{H})^{+}\right], 2638\left[(\mathrm{M}+\mathrm{Na})^{+}\right] ;$FT-IR $\left(\right.$ATR crystal): $v\left(\mathrm{~cm}^{-1}\right)$ $1643(v \mathrm{C}=0)$.

\subsection{Extraction experiments}

Rare earth elements (REEs) stock solutions were prepared at thedesired acidity from 10,000 mg L-1 ICP standard (in $1 \% \mathrm{HNO}_{3}$ ) of Cerium, neodymium, samarium, gadolinium, dysprosium, erbium, and ytterbium. A synthetic solution mimicking the leaching of a magnet was prepared from $1000 \mathrm{mg} \mathrm{L}^{-1} \mathrm{ICP}$ standard (in $1 \% \mathrm{HNO}_{3}$ ) of neodymium, dysprosium, iron and boron. The desired concentrations were prepared by dilution using ultrapure water (MilliQ, Millipore, $>18 \mathrm{M} \Omega \mathrm{cm}^{-1}$ ) and the acidity was adjusted with nitric acid.

Different organic solutions were prepared from CR4-Tz-DDDGA at different specific concentrations in chloroform, toluene/octanol $(90 / 10 \mathrm{v} / \mathrm{v})$, dodecane/octanol $(80 / 20 \mathrm{v} / \mathrm{v})$ or octanol. In some cases, octanol was used as a phase modifier. Indeed, turbid solutions were obtained when solutions without the phase modifier came into contact with $5 \mathrm{M}$ nitric acid. Organic phases were pre-equilibrated with an aqueous phase at the same acidity as in the extraction step without the REE cations. The pre-equilibrated organic phases were then contacted with an equal volume of an aqueous acidic stock solution of REEs in a thermostatic shaker (Infor-ht ${ }^{\circledast}$ Ecotron) at $25^{\circ} \mathrm{C}$ for one hour at $400 \mathrm{rpm}$. The phases were separated after centrifugation at $4000 \mathrm{rpm}$ for $10 \mathrm{~min}$ (Sigma 3-16 PK). After centrifugation, the separated aqueous phases were subjected to ICP/AES analysis in order to determine the distribution ratio $\left(D_{M}\right)$, which is the ratio of the

total concentration of metal $\mathrm{M}$ in the organic phase to the total

concentration of the same metal in the aqueous phase, i.e., $D_{M}=[M] \circ r g /[M] a q$. The experiments were carried out in duplicate measurements with the precision of $\pm 5 \%$. The extraction efficiency ( $\% \mathrm{E}$ ) was determined by using the following equation: $\% E=D /(D+$ Vaq/Vorg $) \times 100 \%$, and the selectivity or separation factor $\left(S_{M 1} / M_{2}\right)$ is given by $S F=D_{M 1} / D_{M 2}$, with $D_{M 1}$ and $D_{M 2}$ being the distribution ratios of the rare-earth ions and rare-earth ions and the competitive ions, respectively.

\subsection{Stripping}

Stripping of lanthanides was performed by treating the loaded organic phase with a solution of ammonium carbonate or ammonium oxalate (typically $0.5 \mathrm{M}$ ). The stripping of permanent magnets was performed by treating the loaded organic phase with a solution of ammonium carbonate, ammonium oxalate (typically $0.5 \mathrm{M}$ ) or pure water (MilliQ). Back-extractions were performed at room temperature $\left(22-24^{\circ} \mathrm{C}\right.$ ) by contacting equal volumes of organic and aqueous phases during $1 \mathrm{~h}$ (ratio aqueous over organic phase $A / O=1$ or 5 . After separation by centrifugation ( $4000 \mathrm{rpm}$ for $10 \mathrm{~min}$ ), metals concentrations 
were measured in the aqueous phase by ICP/AES. The stripping percentage (\%S) was calculated as follows: \%S [M]aq/[M]org $x 100 \%$. The experiments were carried out in duplicate measurements with a precision of $\pm 5 \%$.

\section{Results and discussion}

\subsection{Synthesis and characterizations of CR4-Tz and CR4-TZ-DDDGA}

The calix(4)resorcinarene based cavitands were synthesized via a general synthetic approach, as illustrated in Fig. 2. The cavitands' syntheses were performed starting with the azide calix(4)resorcinare (3) which was synthesized as described in our previous work [17]. CR4-Tz and CR4-Tz-DDDGA were synthesized by a click linkage between octyne or a "clickable DDDGA" respectively with the azide calix(4)resorcinare (3) under the $\mathrm{Cu}(\mathrm{I})$-catalyzed condition using $\mathrm{CuBr}\left(\mathrm{PPh}_{3}\right)_{3}$ as the catalyst. The "clickable DDDGA" (2) was prepared by amide coupling of propargylamine with DDDGA using DCC as the coupling agent in the presence of HOBt. DDDGA was prepared by ring opening the diglylcolic anhydride with didecylamine in THF.

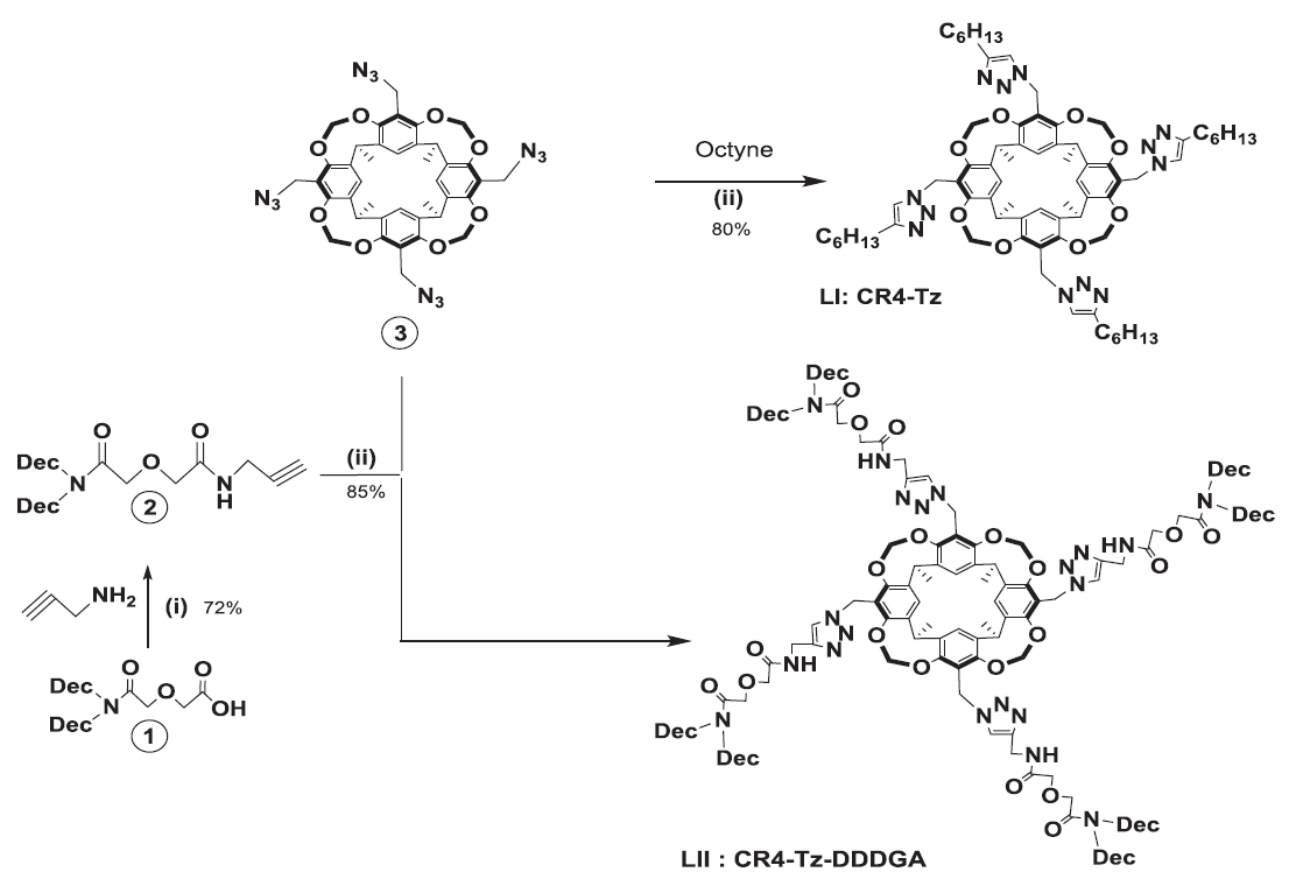

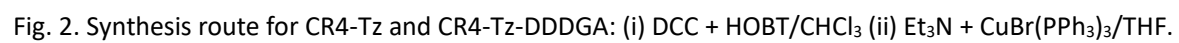

The success of the click reaction was monitored by FT-IR, ${ }^{1} \mathrm{H}$ NMR, ${ }^{13} \mathrm{C}$ NMR, DEPT135, COSY, and HSQC, as well as ESI-MS mass spectrometry (see supporting information). The complete disappearance of the azide stretching vibration at $2090 \mathrm{~cm}^{-1}$ in the IR spectra, and the alkyl $\mathrm{CH}$ signal in the ${ }^{1} \mathrm{H}$ NMR spectra indicates the complete conversion of the $\mathrm{N}_{3}$ and the alkyl groups into the triazole functionalities. In the IR spectra, the formation of a new stretching band at $1644 \mathrm{~cm}^{-1}$ corresponding to the amide groups of the DGA side arms was observed for CR4-Tz-DDDGA. The formation of the triazole rings was further confirmed by the resonance signals at 7.36 and $7.6 \mathrm{ppm}$ in the ${ }^{1} \mathrm{H}$ NMR spectrum corresponding to the triazoles $\mathrm{CH}$ of $\mathrm{CR} 4-\mathrm{Tz}$ and CR4-Tz-DDDGA, respectively, in addition to the appearance of the signals in ${ }^{13} \mathrm{C}$ NMR spectrum corresponding to the triazoles $\mathrm{C}=\mathrm{C}$ at 120.8 and $148.7 \mathrm{ppm}$ for CR4-Tz and at 122.8 and $144.7 \mathrm{ppm}$ for CR4-Tz-DDDGA. Furthermore, the DGA side arms for CR4-Tz-DDDGA were identified by two resonance signals of the $\mathrm{CH}_{2}$ methylene groups at 69.4 and $71.54 \mathrm{ppm}$ and two other signals at $168.1,169.7 \mathrm{ppm}$ in the ${ }^{13} \mathrm{C}$ NMR spectra, corresponding to the amide carbonyl carbons.

\subsection{Application to ion separation}

The extraction experiments were performed using an aqueous solution at $5 \mathrm{M} \mathrm{HNO}_{3}$ and containing seven lanthanides including $\mathrm{Ce}^{3+}, \mathrm{Nd}^{3+}, \mathrm{Sm}^{3+}$ as light rare earth elements (LREEs) and $\mathrm{Gd}^{3+}, \mathrm{Dy}^{3+}, \mathrm{Er}^{3+}$, and $\mathrm{Yb}^{3+}$ as heavy rare earth elements (HREES). Comparison between the efficiency of CR4-Tz and CR4-Tz-DDDGA toward the extraction of the lanthanides from 5 $\mathrm{M} \mathrm{HNO}_{3}$ was carried out in $\mathrm{CHCl}_{3}$. The effects of different parameters such as the influence of the diluents and the effect of the ligand on the extraction performance of lanthanides were investigated. After the extraction experiments, successful recovery of REEs was evaluated using ammonium oxalate, ammonium carbonate and water.

\subsubsection{Influence of triazole functionalities}

Preliminary screening tests were performed in order to evaluate the role of the triazole rings in regards to the extraction properties of the cavitand. The aim was to evaluate whether the nitrogen atoms from the triazoles rings and/or the oxygen atoms of the DGA units are engaged in the complexation of Ln(III). Thus, the extraction performances of LI (CR4-Tz) that contains only four triazoles side arms were compared to those of LII (CR4-Tz-DDDGA) that contains four triazole-DGA side arms. Taking into account the extraction profile of calix(4)resorcinarene-DGA cavitands described in our previous work 
$[16,17]$, and based on our knowledge obtained from these experiments, the extraction of lanthanides in classical diluents by this type of neutral extractants occurs through a solvation mechanism and is influenced by the salting out effect of the aqueous medium. The extraction profile of CR4-Tz-DODGA presented in our previous work showed that the distribution coefficient increased with the increase of feed nitric acid concentration, and the extractant was more efficient at $5 \mathrm{M} \mathrm{HNO}_{3}$ [17].

Therefore, the efficiencies of the two ligands, LI and LII were investigated toward the extraction of $7 \operatorname{Ln}(I I I)$ from a $5 \mathrm{M}$ solution. Due to the precipitation of ligand $\mathbf{L I}$ in other solvents after contact with $5 \mathrm{M} \mathrm{HNO}_{3}$, the extraction studies were performed in $\mathrm{CHCl}_{3}$.

The comparison between the performance of the two extracting phases $4 \mathrm{mM}$ of CR4-Tz and $1 \mathrm{mM}$ of CR4-Tz-DDDGA toward the extraction of the seven lanthanides is illustrated in Fig. 3. The results show that the cavitand LII at $1 \mathrm{mM}$ can extract lanthanides with a relative selectivity toward HREE ( $14 \%$ of Ce up to $52 \%$ of Yb).

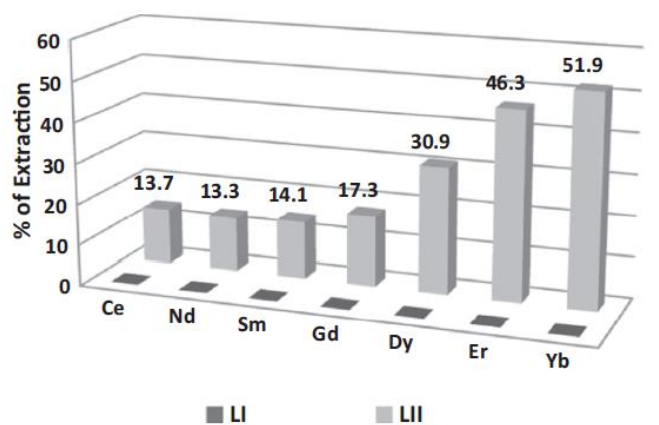

Fig. 3. Percentage of extraction of LI and LII. Extracting phase $[\mathrm{LI}]=4 \mathrm{mM}$ or $[\mathrm{LII}]=1 \mathrm{mM}$ in $\mathrm{CHCl}_{3}$. Aqueous phase: $[\mathrm{Ln}(\mathrm{III})]$ total $=4 \mathrm{mM}\left[\mathrm{HNO}_{3}\right]$ $=5 \mathrm{M}$.

However, no extraction behavior has been observed for LI toward all targeted Ln(III) even using an LI extracting phase that is four times more concentrated than that of LII. These results indicate that the triazoles functionalities are not good candidates for the extraction of lanthanides and therefore are not involved in the extraction of the cavitand LII. The triazole linker is not involved in the extraction as has been shown recently with the use of polydentate neutral organophosphorus ligands fixed on an arene platform via methylene-1,2,3-triazole linkers [21]. While this finding may be attributable to the "softness" of the nitrogen donor ligands enabling moderately efficient $\operatorname{Ln}(\mathrm{III})$ separations [22], the exact origin of the covalency effect in $\mathrm{N}$ donor polydentate ligands is still the subject of ongoing debate and currently is rather poorly understood [23].

The presence of the DGA unit on the CR4-Tz-DDDGA contributes to the extraction of the $\operatorname{Ln}(I I I)$ and to the selectivity for HREEs. Indeed, the diglycolamide have one etheric group and two amidic groups which are considered to act as hard donor atoms. Based on the HSAB concept [9], these atoms binds cationic elements with high charge densities (HREEs) more strongly than those with low charge densities (LREEs). Additionally, the decrease in the atomic size of the REEs from Ce to $\mathrm{Yb}$ (lanthanide contraction) causes a gradual decrease in the basicity of the trivalent rare earth ions and an increase in the stability of complexes along the series which can explain the selectivity for the HREEs [8].

\subsubsection{Effect of the organization of diglycolamides on resorcinarene platform}

The effect of the organization of diglycolamide moieties on the cavitand have been evaluated by comparing the efficiency of the cavitand with respect to TODGA. Experiments have been performed in toluene/ $10 \%$ octanol toward the extraction of the same series of lanthanides as mentioned above from a $5 \mathrm{M} \mathrm{HNO}_{3}$ solution. The data showed that at the experimental concentrations, TODGA was not able to extract the targeted lanthanides and its distribution coefficient was always lower than 1. On the other hand, CR4-TZ-DDDGA showed a good extraction ability especially toward REEs with an increase of the extraction efficiency along the series from $\mathrm{Ce}$ to $\mathrm{Yb}$ following the lanthanide contraction. The quantitative extraction ( $>95 \%)$, of Dy, $\mathrm{Er}$ and $\mathrm{Yb}$, is observed for the CR4-TZ-DDDGA which is much more efficient than the free TODGA $(<50 \%)$. Therefore, this finding indicates the positive effect of the organization of the diglycolamides on the preorganized platform.

A comparison between the efficiency of the cavitand toward the extraction of $\operatorname{Ln}(\mathrm{III})$ with respect to TODGA is represented in the following Fig. 4. 


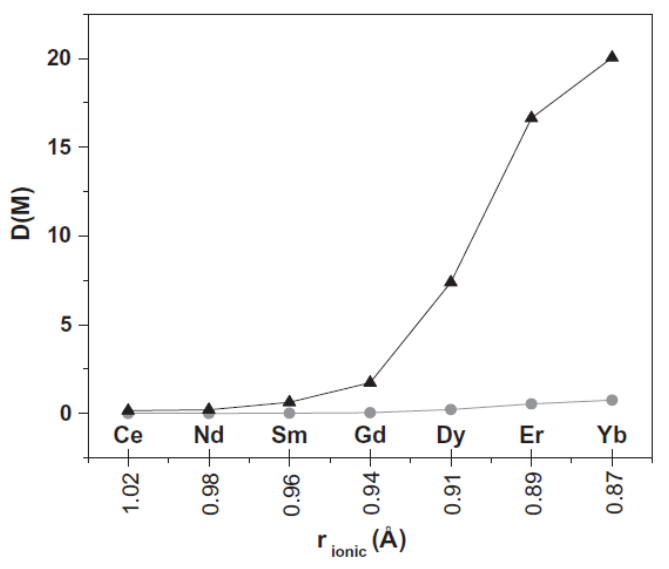

Fig. 4. Comparison between the efficiency of the free diglycolamide TODGA $(O)$ and CR4-TZ-DDDGA $(\triangle)$. Extracting phase $4 \mathrm{mM}$ in toluene/octanol (90/10). Aqueous phase: [ $\mathrm{Ln}(\mathrm{III})]$ total $=4 \mathrm{mM}$ at $5 \mathrm{M}\left[\mathrm{HNO}_{3}\right]$. Elements (trivalent cations) are ordered according to decreasing ionic radii.

\subsubsection{Effect of the diluents and modifier on the distribution coefficient}

A diluent is used generally to decrease the viscosity of the extractant solution, to provide a suitable concentration for the extractant, to decrease the emulsion-forming tendencies of the extractant, and/or to improve the dispersion and coalescence properties of the solvent. A modifier can also be added to the system to overcome the formation of a third phase. It is wellknown that both the diluent and the modifier can affect the extracting agent as well as the extracting species through molecular and supramolecular interactions, affording changes in the efficiency or the extraction equilibrium [24].

The influence of the diluents on the performance of LII has been studied in three different diluents: toluene/10\% octanol, dodecane/20\% octanol, and pure octanol. Octanol was added to toluene and dodecane in order to avoid third phase formation and to enhance the solubility of the cavitand. An extracting phase consisting $4 \mathrm{mM}$ of the extractant calix(4)resorcinarene-DDDGA was investigated toward the extraction/separation of the previously studied seven REEs ( 0.6 $\mathrm{mM}$ of each REEs corresponding to a total amount of $4 \mathrm{mM}$ ) from a $5 \mathrm{M}$ nitric acid solution. The distribution values presented in Fig. 5 indicate that the cavitand in the system toluene/10\% octanol is more efficient toward the extraction of REEs than in dodecane/20\% octanol and in pure octanol. The distribution coefficient values for the extraction of Ln(III) follow the order: $D_{\llcorner n}$ (Toluene) $>D_{\llcorner n}$ (Dodecane) $>D_{\llcorner n}$ (Octanol). The efficiency increases along the series from Ce to $\mathrm{Yb}$ following the lanthanide contraction. The data presented in Fig. 5 shows clearly that irrespective of the diluent, the cavitand is more selective toward the HREEs (Gd(III), Dy(III), Er(III) and Yb(III)) with respect to LREEs (Ce(III), Nd(III), and Sm(III)). The selectivity of LII toward Yb (the $\mathrm{SF}_{(\mathrm{Yb}(\mathrm{III}) / \mathrm{Sm}(\mathrm{III}))}$ was estimated to 45,36 and 31 for the diluent system consisting of octanol, dodecane/octanol and toluene/octanol, respectively. A similar trend for the different diluents was observed for the selectivity.

As a result of the appearance of an intermolecular interaction between the extractant and the modifier, probably due to a complex formation via a hydrogen bond between the macrocycle (DGA moieties) and the alcohol, the distribution of the lanthanides decreases with the addition of octanol, which can explain the lower efficiency in pure octanol. This effect was already observed and studied by IR and NMR spectroscopies by Yoshizuka et al. [25] who investigated the formation of intermolecular complex between LIX-160 (5-dodecylsalicylaldoxime) and tridecanol. A comparison between the effects of toluene and dodecane on the extraction performance of the cavitand in the presence of octanol assumes that a $p$ interaction between octanol and toluene is more favorable than that with the macrocycle, which is probably not the case for dodecane where the interaction between octanol and the cavitand is more favored than that between octanol and dodecane.

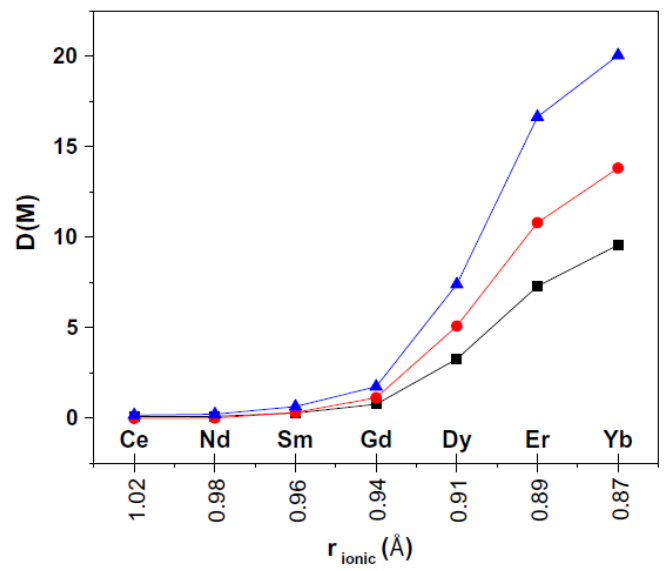

Fig. 5. Influence of diluents on the distribution ratio: toluene/ $10 \%$ octanol $(\triangle)$, dodecane/20\%octanol $(O)$ and octanol $(\square)$. Extracting phase $[\mathrm{LII}]=4 \mathrm{mM}$. Aqueous phase: $[\mathrm{Ln}(\mathrm{III})]$ total $=4 \mathrm{mM}$ at $5 \mathrm{M}\left[\mathrm{HNO}_{3}\right]$. Elements (trivalent cations) are ordered according to decreasing ionic radii. 


\subsubsection{Influence of the concentration of $\mathbf{L I I}$}

The same extraction study carried out for LII in toluene/10\% octanol at $4 \mathrm{mM}$ was then performed at $1 \mathrm{mM}$ and under the same conditions. The results presented in Fig. 6 shows that the extraction performance of Ln(III) by LII decreases sharply after decreasing the concentration of the cavitand. The distribution coefficient of Yb decreased from 20 to 1.6 by decreasing the concentration of LII from $4 \mathrm{mM}$ to $1 \mathrm{mM}$. This is not consistent with the behavior of the separation factors for which upon decreasing the concentration of the cavitand from $4 \mathrm{mM}$ to $1 \mathrm{mM}$, a slight decrease in the separation factors between the successive elements have been observed. However, this decrease is stronger for LREES than for HREES. The SF(Nd/Ce) decreased from 1.69 to 0.76 by decreasing the concentration of LII from $4 \mathrm{mM}$ to $1 \mathrm{mM}$, while the $\mathrm{SF}_{(\mathrm{Yb} / \mathrm{Er})}$ is not affected with this change.

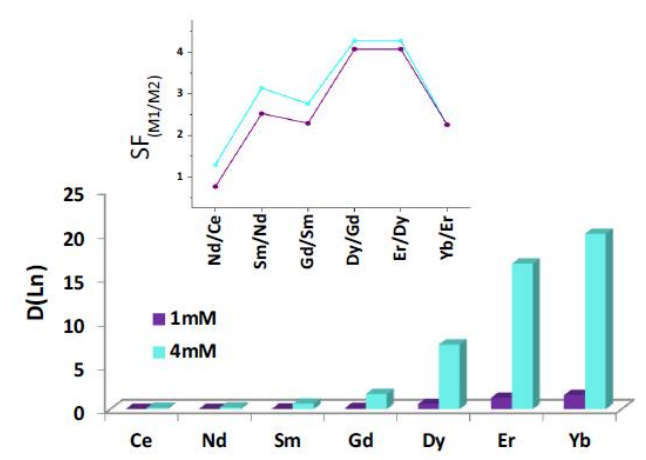

Fig. 6. Influence of the concentration of LII on the extraction performance of $\operatorname{Ln}(I I I)$. Extracting phase [LII] $=1 \mathrm{mM}$ or $4 \mathrm{mM}$ in toluene/octanol (9:1). Aqueous phase: $[\mathrm{Ln}(\mathrm{III})]_{\text {total }}=4 \mathrm{mM},\left[\mathrm{HNO}_{3}\right]=5 \mathrm{M}$.

\subsubsection{Stripping of lanthanides}

After the extraction of REEs from the aqueous phase, the extracting phase is loaded with an amount of REEs initially present in the aqueous phase. Back extraction experiments were carried out to recover the REEs from the extracting phase. Promising results were obtained when stripping experiments were performed using ammonium carbonate and ammonium oxalate with the aqueous to organic phase ratio $\mathrm{A} / \mathrm{O}=1$. The results in Table 1 summarize the extraction of REEs by the extracting phase LII in toluene/octanol and their stripping from this extracting phase. The data show that approximately $50 \%$ of REEs already extracted by LII can be successfully recovered by contacting the extracting phase with ammonium carbonate or ammonium oxalate.

By increasing the ratio, A/O or by performing successive stripping steps, the total amount of the REEs extracted is expected to be recovered.

Table 1 Recovery of REEs from the organic phase: (ratio aqueous over organic phase $A / O=1$ ).

\begin{tabular}{llllllll}
\hline & Ligand/stripping solution & $\mathrm{Ce}$ & $\mathrm{Nd}$ & $\mathrm{Sm}$ & $\mathrm{Gd}$ & $\mathrm{Dy}$ & $\mathrm{Er}$ \\
\hline$\% \mathrm{E}$ & $\mathrm{LII}(1 \mathrm{mM}) /$ Toluene & 3.1 & 2.4 & 5.8 & 12.5 & 36.7 & 56.6 \\
\% & {$\left[\left(\mathrm{NH}_{4}\right)_{2} \mathrm{C}_{2} \mathrm{O}_{4}\right]$ sat. } & 54.3 & 74.8 & 64.2 & 66.0 & 61.8 & 61.6 \\
& $\left.\left[\left(\mathrm{NH}_{4}\right)_{2} \mathrm{CO}_{3}\right]\right](0.5 \mathrm{M})$ & 45.2 & 78.8 & 49.5 & 49.9 & 46.2 & 44.7 \\
\hline
\end{tabular}

Organic phase: $1 \mathrm{mM}$ of CR4DDDGA (LII) in toluene/10\% octanol.

Aqueous phase: saturated solution of ammonium oxalate or $0.5 \mathrm{M}$ solution of ammonium carbonate.

\subsection{Application in permanent magnets}

\subsubsection{Extraction experiments}

Considering the preferential extractability of HREEs by CR4-TZDDDGA, we studied the efficiency and the selectivity of this system toward Dy and $\mathrm{Nd}$ over Fe and B contained in a simulated leaching solution of permanent magnets. An extraction experiment was performed at $5 \mathrm{M}$ nitric acid with equimolar concentration of the metals present in the simulated and the ligand present in the organic phase (toluene/10\% octanol).

As already observed in the previous results, the ligand was selective toward the heavy rare earths HREE, for which it extracted approximately $96 \%$ of Dy(III) compared to $36 \%$ of $\mathrm{Nd}(\mathrm{III})$ with the separation factor $\mathrm{SF}_{(\mathrm{Dy} / \mathrm{Nd})}$ of approximately 38 (Table 2 ). The presented cavitand, CR4-TZ-DDDGA, showed slightly better efficiency with respect to CR4-Tz-DODGA described in our previous work [17] in which at 1:1 ligand to metals ratio, CR4-TZ-DODGA extracted $87 \%$ of Dy(III) compared to only $9 \% \mathrm{Nd}(\mathrm{III})$. Nevertheless, despite its slightly smaller efficiency, CR4-TZ-DODGA showed a much better selectivity SF(Dy/Nd) of 68.

An interesting point in favor of the selective extraction of REEs is that the DB is very low (less than $4 \%$ extracted) and no extraction was observed with respect to Fe (Table 2). Table 2 also confirms the positive effect of the organization of the diglycolamides on the cavitand with the CR4-TZ-DODGA showing much higher efficiency and selectivity than the free ligand. The distribution coefficient and the separation factors of CR4-TZDDDGA toward the targeted lanthanides (Dy and Nd) over the competitive elements $\mathrm{Fe}$ and $\mathrm{B}$ are higher than those of the free TODGA. 
Table 2 Distribution ratio $\mathrm{D}$ of Nd/Dy/Fe/B cations from $5 \mathrm{M}$ HNO3 aqueous feed solution using 6 mM CR4-DDDGA (LII) in toluene/10\% octanol at $25^{\circ} \mathrm{C}$ and their corresponding separation factor SF.

\begin{tabular}{|c|c|c|c|c|c|c|c|c|c|}
\hline & \multicolumn{4}{|l|}{ D } & \multicolumn{5}{|l|}{$S F$} \\
\hline & $\mathrm{Fe}$ & B & $\mathrm{Nd}$ & Dy & $\mathrm{Dy} / \mathrm{Nd}$ & $\mathrm{Dy} / \mathrm{B}$ & $\mathrm{Dy} / \mathrm{Fe}$ & $\mathrm{Nd} / \mathrm{B}$ & $\mathrm{Nd} / \mathrm{Fe}$ \\
\hline LII & $<0.01$ & 0.04 & 0.57 & 21.71 & 38 & 543 & $>2170$ & 14 & $>57$ \\
\hline TODGA & $<0.01$ & 0.06 & 0.02 & 0.44 & 22 & 7 & $>44$ & 0.3 & $>2$ \\
\hline
\end{tabular}

[Lig.] $=6 \mathrm{mM},[\mathrm{M}]_{\mathrm{t}}=6 \mathrm{mM}, 70 \% \mathrm{Fe}, 10 \% \mathrm{Dy}, 10 \% \mathrm{Nd}, 10 \% \mathrm{~B}$.

The present results demonstrate the potential of CR4-DDDGA toward the selective extraction of REE with respect to competitive ions especially iron, $\mathrm{SF}_{(\mathrm{Dy} / \mathrm{Fe})}>10,855$, which is the main competitive ion in the nitric acid leaching solution of $\mathrm{Nd}$ Fe-B permanent magnets.

\subsubsection{Stripping}

After the extraction step, the loaded organic solution contains approximately $96 \%$ of Dy and $36 \%$ of Nd initially present in the acid solution. Back-extraction experiments were implemented to quantitatively strip Dy or Dy and $\mathrm{Nd}$ from the extracting phase using ammonium carbonate, ammonium oxalate and deionized water.

As shown in Table 3, Dy and $\mathrm{Nd}$ can be mainly recovered after stripping the extracting phase with the ammonium carbonate or ammonium oxalate and even with water. The quantitative recovery of the extracted $\mathrm{Nd}$ and Dy can be attained by contacting the extracting phase with the stripping aqueous phases at the $\mathrm{A} / \mathrm{O}$ ratio $=5$. It was observed that superior recovery of the REE is obtained by using a saturated solution of ammonium oxalate as the stripping solution.

Table 3 Recovery of REEs from the extracting phase (aqueous to organic phase ratio A/O = 1 or 5 ).

\begin{tabular}{|c|c|c|c|c|}
\hline & & Ligand/stripping solution & $\mathrm{Nd}$ & Dy \\
\hline$\% \mathrm{E}$ & & LII/toluene & 36 & 96 \\
\hline \multirow[t]{6}{*}{$\% \mathrm{~S}$} & $\mathrm{~A} / \mathrm{O}=1$ & {$\left[(\mathrm{NH} 4)_{2} \mathrm{C}_{2} \mathrm{O}_{4}\right]$ Sat. } & 69 & 61 \\
\hline & & {$\left[(\mathrm{NH} 4)_{2} \mathrm{CO}_{3}\right](0.5 \mathrm{M})$} & 38 & 40 \\
\hline & & $\mathrm{H}_{2} \mathrm{O}$ & 41 & 67 \\
\hline & $\mathrm{A} / \mathrm{O}=5$ & {$\left[(\mathrm{NH} 4)_{2} \mathrm{C}_{2} \mathrm{O}_{4}\right]$ Sat. } & 100 & 100 \\
\hline & & $\left.\left[(\mathrm{NH} 4)_{2} \mathrm{CO}_{3}\right](0.5 \mathrm{M})\right)$ & 82 & 96 \\
\hline & & $\mathrm{H}_{2} \mathrm{O}$ & 84 & 92 \\
\hline
\end{tabular}

Organic phase: $6 \mathrm{mM}$ CR4DDDGA (LII) in toluene/10\% octanol); aqueous solution saturated solution of ammonium oxalate, $0.5 \mathrm{M}$ solution of ammonium carbonate, or pure water.

\section{Conclusions}

A comparative study of the extractability of seven $\mathrm{Ln}(\mathrm{III})$ (Ce(III), Nd(III), Sm(III), Gd(III), Dy(III), $\operatorname{Er}(\mathrm{III}), \mathrm{Yb}(\mathrm{III}))$ from $5 \mathrm{M} \mathrm{HNO}_{3}$ aqueous solution by a cavitand containing triazoles rings LI (CR4-Tz) and another cavitand containing triazoles ring and DGA units LII (CR4-Tz-DDDGA) established that the triazoles rings are not involved in the complexation of lanthanides. An investigation of the influence of the three diluents on the distribution coefficients and the separation factors of LII toward 7 lanthanides from $5 \mathrm{M} \mathrm{HNO}_{3}$ concluded that the diluent affects the distribution ratios and did not affect the selectivity between the lanthanides. LII was efficient for the extraction of HREEs. Selective extraction and recovery of Ln(III) mimicking a leaching solution of $\mathrm{Nd} / \mathrm{Dy} / \mathrm{Fe} / \mathrm{B}$ magnets allowed us to consider this ligand for the extraction of REEs present in a mimicking solution of $\mathrm{Nd} / \mathrm{Dy} / \mathrm{Fe} / \mathrm{B}$ magnets. By varying the concentration of the ligand as described in our previous work, selective extraction of dysprosium or mutual extraction of both lanthanides can be attained.

\section{Acknowledgments}

We gratefully acknowledge the financial support for this project provided by the Lebanese University, CEDRE program, CNRS$\mathrm{L}$ (the National Council for Scientific Research. Lebanon), French CNRS, Montpellier University and the Labex Project CheMISyst (ANR- 10-LABX-05-01).

\section{Appendix A. Supplementary material}

Supplementary data associated with this article can be found, in the online version.

\section{References}

[1] Y. Kanazawa, M. Kamitani, J. Alloy. Compd. 408-412 (2006) 1339-1343.

[2] C. Koopman, G.J. Witkamp, Hydrometallurgy 58 (2000) 51-60.

[3] Balakrishnan Ramesh Babu, Anand Kuber Parande Chiya Ahmed Basha, Waste Manage. Res. 25 (2007) 307-318.

[4] (a) Report on critical raw materials for the EU, Critical raw materials profiles, European Commission, 2010; (b) Critical Materials Strategy, U.S. Department of Energy, 2011; (c) J. Seaman, Rare Earths and Clean Energy: Analyzing China's Upper Hand., Institut francais des relations internationales, 2010.

[5] M.K. Jha, A. Kumari, R. Panda, J. Rajesh Kumar, K. Yoo, J.Y. Lee, Hydrometallurgy 165 (Part 1) (2016) 2-26.

[6] K. Binnemans, P.T. Jones, B. Blanpain, T. Van Gerven, Y. Yang, A. Walton, M. Buchert, J. Clean. Prod. 51 (2013) 1-22.

[7] C. Huang, Z. Bian, Rare Earth Coordination Chemistry, John Wiley \& Sons Ltd (2010) 1-39.

[8] N.V. Thakur, Miner. Process. Extr. Metall. Rev. 21 (2000) 277-306. 
[9] R.G. Pearson, J. Chem. Educ. 45 (1968) 581.

[10] K. Matloka, A. Gelis, M. Regalbuto, G. Vandegrift, M.J. Scott, Dalton Trans. (2005) 3719-3721.

[11] S.A. Ansari, P. Pathak, P.K. Mohapatra, V.K. Manchanda, Chem. Rev. 112 (2012) 1751-1772.

[12] S.A. Ansari, P. Pathak, P.K. Mohapatra, V.K. Manchanda, Separat. Purif. Rev. 40 (2011) 43-76.

[13] (a) M. Iqbal, P.K. Mohapatra, S.A. Ansari, J. Huskens, W. Verboom, Tetrahedron 68 (2012) 7840-7847; (b) A. Sengupta, P.K. Mohapatra, M. Iqbal, J. Huskens, W. Verboom, Dalton Transactions 41 (2012) 6970-6979.

[14] H. Huang, S. Ding, N. Liu, Y. Wu, D. Su, S. Huang, Sep. Purif. Technol. 123 (2014) 235-240.

[15] L. Wu, Y. Fang, Y. Jia, Y. Yang, J. Liao, N. Liu, X. Yang, W. Feng, J. Ming, L. Yuan, Dalton Trans. 43 (2014) 3835-3838.

[16] M. Wehbie, G. Arrachart, I. Karame, L. Ghannam, S. Pellet-Rostaing, New J. Chem. 40 (2016) 9344-9351.

[17] M. Wehbie, G. Arrachart, I. Karamé, L. Ghannam, S. Pellet-Rostaing, Separat. Purif. Technol. 169 (2016) 17-24.

[18] H.C. Kolb, M.G. Finn, K.B. Sharpless, Angew. Chem. Int. Ed. 40 (2001) 2004-2021.

[19] H.H. Dam, D.N. Reinhoudt, W. Verboom, Chem. Soc. Rev. 36 (2007) 367-377.

[20] S. Taktak, R. Weissleder, L. Josephson, Langmuir 24 (2008) 7596-7598.

[21] A.N. Turanov, V.K. Karandashev, E.V. Sharova, G.K. Genkina, O.I. Artyushin, RSC Adv. 5 (2015) 27640-27648.

[22] Z. Kolarik, Chem. Rev. 108 (2008) 4208-4252.

[23] (a) A.J. Gaunt, M.P. Neu, Comptes Rendus Chimie 13 (2010) 821-831; (b) M. Trumm, B. Schimmelpfennig, Molecular Physics 114 (2016) 876-883.

[24] J. Rey, S. Dourdain, L. Berthon, J. Jestin, S. Pellet-Rostaing, T. Zemb, Langmuir 31 (2015) 7006-7015.

[25] K. Yoshizuka, H. Arita, Y. Baba, K. Inoue, Hydrometallurgy 23 (1990) 247-261. 